\title{
PEMANFAATAN LAHAN DI KECAMATAN RATAHAN, KECAMATAN RATAHAN TIMUR DAN KECAMATAN PASAN KABUPATEN MINAHASA TENGGARA BERDASARKAN ZONA AGROEKOLOGI DENGAN MENGGUNAKAN SISTEM INFORMASI GEOGRAFIS
}

\author{
As tri Vandalia Elisabeth Naray \\ Johan Alexander Rombang \\ Jaelani Husain
}

\begin{tabular}{ll}
\hline Naskah diterima melalui Website Jurnal Ilmiah agrisosioekonomi@unsrat.ac.id & $:$ Rabu, 13 Februari 2019 \\
Disetujui diterbitkan & : Jumat, 19 Juli 2019 \\
\hline
\end{tabular}

\begin{abstract}
This study aims to determine the direction of land use in Ratahan Subdistrict, Ratahan Timur and Pasan, Southeast Minahasa Regency, based on the Agroecology Zone using the application of Geographic Information Systems (GIS). The type of research used in this study is quantitative research with a method of data and spatial interpretation. The types of data used in the study are primary data and secondary data. The data generated is arranged in the form of information and spatial. The study was conducted in 3 (three) subdistricts namely Ratahan Subdistrict, Ratahan Timur Subdistrict and Pasan Subdistrict, Southeast Minahasa Regency, North Sulawesi Province, which were included in 1 (one) sub-district, Ratahan Sub-district. While the implementation time in April to June 2018. Analysis of the data used in this study where the resulting data is arranged in the form of data and spatial information, then compiling and analyzing data using the Quantum ArcGIS version 10.2 program application. Besides that, biophysical data analysis and agricultural potential data will be carried out. The results of the study based on the concept of land use in Ratahan Subdistrict, East Ratahan and Pasan results of agroecological zone maps using GIS obtained 32 zones from the results of analysis of soil type and slope data and climate type. The results of the analysis of the allocation in accordance with the conditions of land use (land cover) as well as the output of the map of Southeast Minahasa Regency RTRW space map in 2013, the agroecological zone can be divided into two main uses, namely protected zone and cultivation zone. In protected areas recommended in protected forests, water catchment areas, river borders and lake borders around the springs. Whereas in the cultivation area it is recommended to use land for agroforesty, rice fields, settlements, mixed farming, conservation settlements, plantations and production forest. ${ }^{*}$ eprm*
\end{abstract}

Keywords: ArcGIS versi 10.2 application. program application, climate type, soil type, slope

\section{ABSTRAK}

Penelitian ini bertujuan untuk menentukan arahan pemanfaatan lahan di Kecamatan Ratahan, Ratahan Timur dan Pasan Kabupaten Minahasa Tenggara berdasarkan Zona Agroekologi dengan menggunakan aplikasi Sistem Informasi Geografis (SIG). Jenis penelitian yang digunakan dalam penelitian ini jenis penelitian kuantitatif dengan pendekatan metode interpretasi data dan spasial. Jenis data yang digunakan dalam penelitian adalah data primer dan data sekunder. Data tersebut yang dihasilkan disusun dalam bentuk informasi dan spasial. Penelitian dilaksanakan pada 3 (tiga) kecamatan yakni Kecamatan Ratahan, Kecamatan Ratahan Timur dan Kecamatan Pasan Kabupaten Minahasa Tenggara Provinsi Sulawesi Utara yang sebelum pemekaran tercakup dalam 1 (satu) kecamatan yaitu Kecamatan Ratahan. Sedangkan waktu pelaksanaan pada bulan April sampai Juni 2018. Analisis data yang digunakan dalam penelitian ini dimana data yang dihasilkan disusun dalam bentuk informasi data dan spasial, kemudian dilakukan kompilasi dan analisis data dengan menggunakan aplikasi program Quantum ArcGIS versi 10.2. Disamping itu akan dilakukan analisis data biofisik dan data potensi pertanian. Hasil penelitian berdasarkan konsep pemanfaatan lahan di Kecamatan Ratahan, Ratahan Timur dan Pasan hasil peta zona agroekologi dengan menggunakan SIG diperoleh 32 zona dari hasil analisis data jenis tanah dan kemiringan lereng serta tipe iklim. Hasil analisis peruntukannya yang sesuai dengan kondisi penggunaan lahan (tutupan lahan) serta keluaran peta pola ruang RTRW Kabupaten Minahasa Tenggara tahun 2013 maka zona agroekologi dapat dibedakan dalam dua penggunaan utama yaitu zona kawasan lindung dan zona budidaya. Pada kawasan lindung direkomendasikan pada hutan lindung, daerah resapan air, sempadan sungai dan semp adan danau kawasan sekitar mata air. Sedangkan pada kawasan budidaya direkomendasikan penggunaan lahan untuk agroforesty, sawah, permukiman, pertanian campuran, pemukiman konservasi, perkebunan serta hutan produksi. ${ }^{*}$ prm*

Kata kunci: aplikasi ArcGIS versi 10.2, tipe iklim, jenis tanah, kemiringan lereng 


\section{PENDAHULUAN}

\section{Latar Belakang}

Penggunaan lahan merupakan salah satu variabel kunci dalam kajian yang terkait dengan perencanaan wilayah dan pengelolaan sumberdaya lahan. Sayangnya, meskipun telah diakui arti pentingnya, informasi penggunaan lahan tetap sulit diperoleh, khususnya apabila kualitas, relevansi dan kemutakhiran data yang menjadi kriteria utama. Persoalan muncul ketika ingin melakukan analisis data spasial untuk evaluasi dan perencanaan ruang ternyata kandungan informasi penggunaan lahan yang berbeda-beda dan tidak konsisten secara multi-temporal.

Untuk menghasilkan informasi spasial tentang lahan diperlukan identifikasi dan evaluasi potensi sumberdaya lahan. Potensi dan penggunaan lahan disetiap wilayah berbeda-beda tergantung pada kondisi kualitas dan karakteristik lahan yang ditentukan oleh faktor tanah, topografi dan iklim. Adanya keragaman sifat-sifat tanah, topografi dan iklim dapat digunakan sebagai dasar pemilihan berbagai komoditi yang sesuai untuk dikembangkan disuatu wilayah (FAO, 1976).

Penerapan teknologi sistem usaha tani harus didasarkan pada kajian penggunaan lahan. Salah satunya yakni kajian zona agroekologi untuk mendapatkan pewilayahan komoditas pertanian yang disesuaikan pelestarian sumberdaya alam dan lingkungan sekitar. Sehingga dapat memberi informasi mengenai penggunaan lahan, rekomendasi penggunaan pupuk pada suatu wilayah dan komoditas unggulan dan mempermudah dalam melaksanakan kegiatan pertanian pada akhirnya menghasilkan produk yang unggulan.

Kabupaten Minahasa Tenggara (MITRA) merupakan kabupaten pemekaran dari Kabupaten Minahasa Selatan. Lokasi penelitian di tiga Kecamatan yaitu Kecamatan Pasan, Ratahan dan Ratahan Timur yangtermasuk dalam wilayah pemerintahan Kabupaten Minahasa Tenggara.

Pasal 28 Peraturan Daerah Kabupaten Minahasa Tenggara Nomor 3 Tahun 2013 tentang Rencana Tata Ruang Wilayah Kabupaten Minahasa Tenggara Tahun 2013-2033, berbunyi sebagai berikut: (1) Kawasan peruntukan pertanian sebagaimana dimaksud dalam Pasal 26 huruf c, terdiri atas: a. kawasan pertanian tanaman pangan, b. kawasan pertanian hortikultura; c. kawasan perkebunan; dan d. kawasan peternakan.
Ketersediaan dan pemanfaatan baik data maupun informasi tentang zona agroekologi, iklim serta sumber daya lahan yang berbasis teknologi komputer seperti Sistem Informasi Geografis (GIS) dapat memudahkan pemetaan zona agroekologi dan alternatif dalam pengembangan komoditi pertanian sehingga akan membantu dalam penentuan pemanfaatan masing-masing lahan. Analisis zona agroekologi bisa dilakukan dengan memanfaatkan teknologi SIG, dimana keunggulan teknologi ini dapat digunakan untuk menentukan zonifikasi lahan yang sesuai dengan karakteristik lahan yang ada. SIG dapat membantu pembuatan perencanaan masing-masing wilayah tersebut dan hasilnya dapat digunakan sebagai acuan.

Berdasarkan hal tersebut diatas maka perlu dilakukan penelitian pemanfaatan lahan di Kabupaten Minahasa Tenggara khususnya di Kecamatan Ratahan, Kecamatan Ratahan Timur serta Kecamatan Pasan berdasarkan Zona Agroekologi dengan menggunakan aplikasi Sistem Informasi Geografis agar pemanfaatan lahan serta penerapan teknologi pertanian lebih efisien dan efektif.

\section{Perumusan Masalah}

Upaya peningkatan produksi yang berkelanjutan pada sektor pertanian di Kecamatan Ratahan, Ratahan Timur dan Pasan Kabupaten Minahasa Tenggara salah satunya pemanfaatan lahan secara tepat sehingga memudahkan dalam perencanaan dan pengelolaannya. Permasalahan yang dapat dirumuskan sehubungan dengan latar belakang tersebut diatas adalah : Bagaimana konsep pemanfaatan lahan di Kecamatan Ratahan, Ratahan Timur dan Pasan Kabupaten Minahasa Tenggara berdasarkan Zona Agroekologi dengan menggunakan Aplikasi Sistem Informasi Geografis (GIS).

\section{Tujuan Penelitian}

Penelitian ini bertujuan untuk menentukan arahan pemanfaatan lahan di Kecamatan Ratahan, Ratahan Timur dan Pasan Kabupaten Minahasa Tenggara berdasarkan Zona Agroekologi dengan menggunakan aplikasi Sistem Informasi Geografis (SIG).

\section{Manfaat Penelitian}

Manfaat yang diharapkan dari penelitian ini adalah dapat memberikan informasi bagi para penentu kebijakan pemanfaatan lahan khususnya di Kecamatan Ratahan, Ratahan Timur dan Pasan Kabupaten Minahasa Tenggara dan juga dapat memberikan kontribusi ilmiah kepada para peneliti selanjutnya. 


\section{METODE PENELITIAN}

\section{Jenis Penelitian}

Jenis penelitian yang digunakan dalam penelitian ini jenis penelitian kuantitatif dengan pendekatan metode interpretasi data dan spasial. Jenis data yang digunakan dalam penelitian adalah data primer dan data sekunder. Data tersebut yang dihasilkan disusun dalam bentuk informasi dan spasial.

\section{Tempat dan Waktu Penelitian}

Penelitian dilaksanakan pada 3 (tiga) Kecamatan yakni Kecamatan Ratahan, Kecamatan Ratahan Timur dan Kecamatan Pasan Kabupaten Minahasa Tenggara Provinsi Sulawesi Utara yang sebelum pemekaran tercakup dalam 1 (satu) kecamatan yaitu Kecamatan Ratahan. Sedangkan waktu pelaksanaan pada bulan April sampai Juni 2018.

\section{Bahan dan Peralatan}

Bahan yang di gunakan adalah peta administrasi Kabupaetn Minahasa Tenggara skala 1:50.0000, peta lereng skala 1:50.000, peta RTRW Kabupaten Minahasa Tenggara Tahun 2013 skala 1:50.000, peta tanah skala 1:50.000,peta curah hujan hasil analisis Poligon Thiessen Tahun 2018 skala 1:50.000, peta elevasi skala 1:50.000, peta tutupan lahan hasil digitasi pada skala $1: 10.000$ dari digital globe tahun 2017 skala 1:20.000 serta peralatan komputer (PC dan Laptop) dengan Aplikasi Quantum ArcGIS versi 10,2, Printer, Alat tulis menulis, Camera digital dan peralatan lainnya.

\section{Analisis Data}

Analisis data yang digunakan dalam penelitian ini dimana data yang dihasilkan disusun dalam bentuk informasi data dan spasial, kemudian dilakukan kompilasi dan analisis data dengan menggunakan aplikasi program Quantum ArcGIS versi 10.2. Disamping itu akan dilakukan analisis data biofisik, data potensipertanian yang disusun dalam suatu sistem basis data dilakukan melalui kompilasi data dengan peta administrasi Kecamatan Ratahan, Ratahan Timur dan Pasan dengan menggunakan program Quantum ArcGIS versi 10.2 dari peralatan komputer (PC dan Laptop).

berikut:

\section{Prosedur Pelaksanaan Penelitian}

Prosedur pelaksanaan penelitian sebagai

1. Pengumpulan Data

Data yang digunakan dalam penelitian ini adalah data primer dan data sekunder. Pengumpulan data primer dilakukan melalui pengamatan (observasi) di lapangan. Kegiatan observasi dilaksanakan untuk mendapatkan informasi keadaan lapangan melalui pengambilan gambar dengan menggunakan kamera digital. Data primer tersebut yang akan dikumpulkan diantaranya:

a. Penggunaan lahan pertanian di tingkat petani yang disertai pengambilan gambar bentuk penggunaan lahan di Kecamatan Ratahan, Ratahan Timur dan Pasan.

b. Observasi/pengamatan jenis penutupan lahan

Pengumpulan data sekunder dilakukan pada instansi pemerintah yang terkait dengan kegiatan penelitian, data sekunder yang dikumpulkan seperti pada Tabel 1 Sumber Data Pembuatan Peta dibawah ini:

Tabel 1. Sumber Data Pembuatan Peta

\begin{tabular}{|c|c|c|c|}
\hline No & Data & Sumber Data & Keterangan \\
\hline 1. & $\begin{array}{l}\text { Data Keadaan Umum } \\
\text { Kecamatan Ratahan, } \\
\text { Ratahan Timur dan } \\
\text { Kecamatan Pasan }\end{array}$ & $\begin{array}{l}\text { Kecamatan Ratahan, Ratahan } \\
\text { Timur dan Kecamatan Pasan } \\
\text { Kabupaten MinahasaTenggara }\end{array}$ & \\
\hline 2. & Peta Jenis Tanah & $\begin{array}{c}\text { B A P E D A } \\
\text { Kabupaten Minahasa Tenggara }\end{array}$ & Skala $1: 50.000$ \\
\hline 3. & Peta Curah Hujan & $\begin{array}{l}\text { Hasil Analisis } \\
\text { Poligon Thiessen Tahun } 2018\end{array}$ & Skala $1: 50.000$ \\
\hline 4. & Peta Kelas Lereng & $\begin{array}{c}\text { B A P E D A } \\
\text { Kabupaten Minahasa Tenggara }\end{array}$ & Skala 1: 50.000 \\
\hline 5. & Peta Penggunaan Lahan & $\begin{array}{l}\text { Hasil Digitasi pada Skala1 : } 10.000 \\
\text { dari Digital Globe Tahun } 2017\end{array}$ & Skala $1: 20.000$ \\
\hline 6. & $\begin{array}{l}\text { Peta RTRW Kabupaten } \\
\text { Minahasa Tenggara }\end{array}$ & $\begin{array}{c}\text { B A P E D A } \\
\text { Kabupaten Minahasa Tenggara }\end{array}$ & Skala $1: 50.000$ \\
\hline 7. & $\begin{array}{l}\text { Peta Administrasi } \\
\text { Kecamatan }\end{array}$ & $\begin{array}{c}\text { B A P E D A } \\
\text { Kabupaten Minahasa Tenggara }\end{array}$ & Skala 1:50.000 \\
\hline 8. & Peta Elevasi & $\begin{array}{c}\text { BAPEDA } \\
\text { Kabupaten Minahasa Tenggara }\end{array}$ & Skala 1:50.000 \\
\hline
\end{tabular}

Tabel 1 digunakan untuk menentukan arahan pemanfaatan atau penggunaan lahan berdasarkan zona agroekologi masing-masing wilayah.

2. Pre-Prosesing Data

Tahap awal dalam analisis zona agroekologi Kecamatan Pasan, Ratahan dan Ratahan Timur adalah pengumpulan data sekunder (peta) yang kemudian dimasukkan dalam folder dalam ArcGis sebagai tempat untuk penyimpanan data melalui catalog sebagai folder geodatabase.

3. Tahapan Overlay

Tahapan overlay atau tumpang susun data untuk analisis zona agroekologi dan teknik overlay dimana setelah data sekunder (peta) yang telah ada dalam folder di pindahkan atau di import melalui geoprosesing dengan intersect. Pada tahap overlay ini tahapan tumpang susun antara peta kelas lereng, peta jenis tanah dan peta curah hujan, sehingga diperoleh 32 (tiga puluh dua) zona dari 178 poligon. Untuk mendapatkan atau membuat peta rekomendasi, maka peta ZAE di overlay dengan peta administrasi, tutupan lahan, elevasi serta peta pola ruang RTRW Tahun 2013. 
Dalam prosedur penelitian ini proses penyusunan peta zona agroekologi Kecamatan Ratahan, Ratahan Timur dan Kecamatan Pasan Kabupaten Minahasa Tenggara digambarkan dalam bentuk Diagram Alir (Gambar 1).

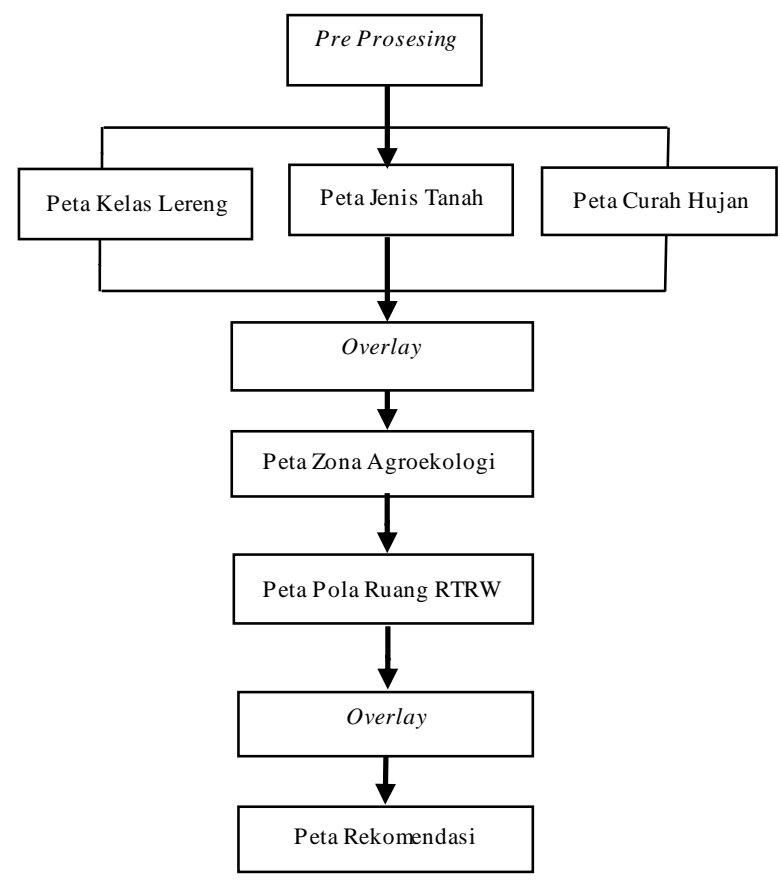

Gambar 1. Diagram alir prosedur penyusunan peta zona agroekologi di Kecamatan Ratahan, Ratahan Timur dan Kecamatan Pasan

\section{HASIL PEMBAHASAN}

\section{Kondisi Agroekologi Daerah Penelitian}

\section{Lereng}

Hasil analisis digitasi dan kompilasi data lereng di Kecamatan Pasan, Ratahan dan Ratahan Timur terdapat pada Tabel 2.

Tabel 2. Luas Wilayah, Lereng dan Bentuk Wilayah Daerah

\begin{tabular}{lllr}
\multicolumn{4}{c}{ Penelitian } \\
\hline Kecamatan & Bentuk Wilayah & Lereng & Luas (Ha) \\
\hline Ratahan & Datar Berombak & $0-8 \%$ & - \\
& Berombak/Bergelombang & $8-15 \%$ & 267,4299 \\
& Berombak berbukit & $15-25 \%$ & $4.177,0224$ \\
& Agak curam/ curam & $25-40 \%$ & 925,2223 \\
& Bergunung & $>40 \%$ & 793,7979 \\
Ratahan & Datar Berombak & $0-8 \%$ & - \\
Timur & Berombak/Bergelombang & $8-15 \%$ & 239,3501 \\
& Berombak berbukit & $15-25 \%$ & $3.891,6263$ \\
& Agak curam/ curam & $25-40 \%$ & $1.520,3952$ \\
& Bergunung & $>40 \%$ & 734,6270 \\
Pasan & Datar Berombak & $0-8 \%$ & 14,0554 \\
& Berombak/Bergelombang & $8-15 \%$ & $1.090,6510$ \\
& Berombak berbukit & $15-25 \%$ & $2.468,2829$ \\
& Agak curam/ curam & $25-40 \%$ & $1.157,5452$ \\
& Bergunung & $>40 \%$ & 246,5176 \\
\hline Jumlah & \multicolumn{3}{c}{$17.526,5238$} \\
\hline Sumber $:$ & Hasil analisis data lereng Kecamatan Ratahan, \\
& Ratahan Timur dan Kecamatan Pasan
\end{tabular}

Kemiringan lereng juga merupakan salah satu gejala perkembangan tanah akibat pengaruh lingkungan fisik dan hayati, dan kelas kemiringan lereng daerah penelitian dimana penyebaran lebih jelasnya dapat dilihat di Gambar 2.

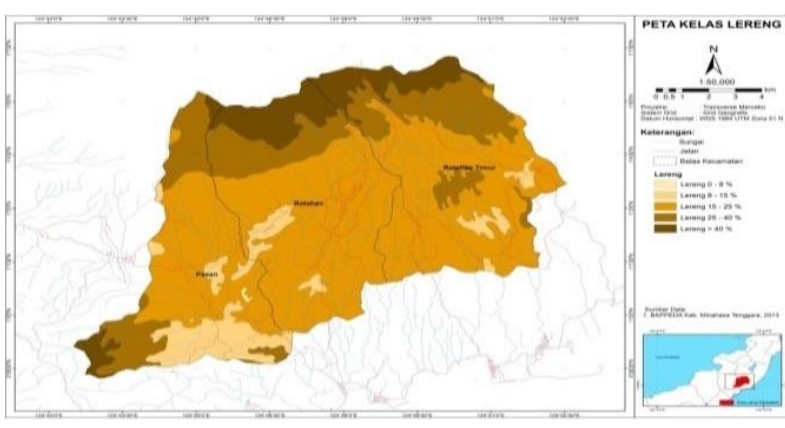

Gambar 2. Peta Kelas Lereng di Kecamatan Pasan, Ratahan dan Ratahan Timur

\section{Curah Hujan}

Hasil analisis data rata- rata curah hujan selama 5 (lima) tahun dari 3 (tiga) alat pos curah hujan yang ada di Kabupaten Minahasa Tenggara yang dituangkan pada Tabel 3 .

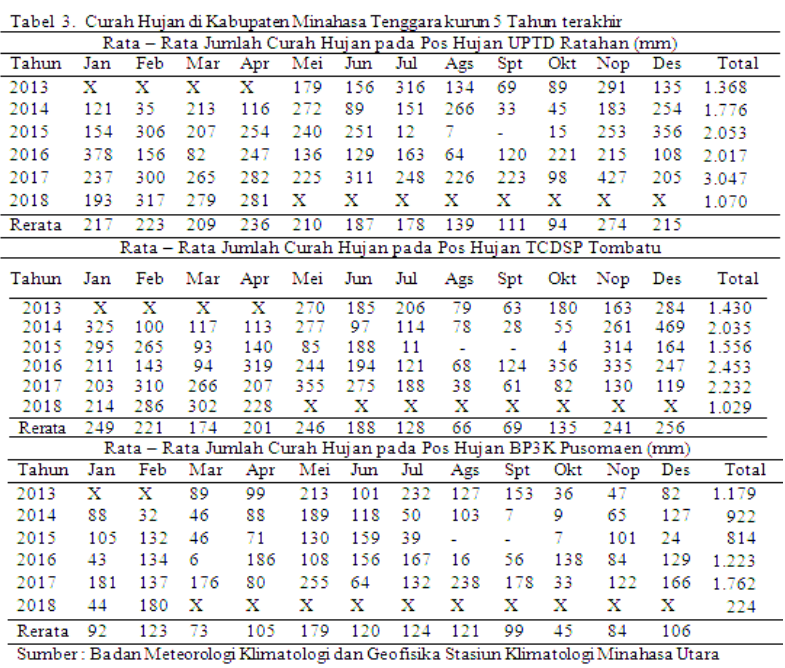

Tabel 3 menunjukkan bahwa dari 3 alat pos curah yang ada secara umum di Kabupaten Minahasa Tenggara selang tahun 2013 sampai dengan April 2018 memiliki curah hujan rata-rata normal kategori menengah (100-300 mm), kecuali pada pos pengamat hujan dari lokasi BP3K Pusomaen yang umumnya memiliki kategori rendah (45-99 mm). Pada pengamatan pos hujan di lokasi UPTD Ratahan berdasarkan kriteria dalam klasifikasi iklim Oldeman diklasifikasikan dalam iklim oldeman tipe B1 (Oldeman L.R dan Darmayanti, 1977). 
Pada pos hujan di TCDSP Tombatu berdasarkan rata-rata curah hujan selang tahun 2013 hingga April 2018 bulan Agustus dan tergolong pada bulan kering jatuh pada bulan Agustus dan September. Sehingga dapat diklasifikasikan pada tipe iklim Oldeman C2. Rata-rata curah hujan pada pos pengamat curah hujan di lokasi BP3K Pusomaen umumnya tergolong pada bulan lembab dan kering hal tersebut dikarenakan lokasi pengamatan berada pada wilayah pesisir pantai dan diklasifikasikan dalam iklim Oldeman tipe E.

Keadaan curah hujan yang merupakan salah satu unsur penting dalam penentuan zona agroekologi yang merupakan hasil analisis poligon thiessen dengan data curah hujan yang diperoleh dari 3 (tiga) pos pengataman curah hujan yang ada di Kabupaten Minahasa Tenggara. lebih jelasnya pada dapat dilihat pada Gambar 3.

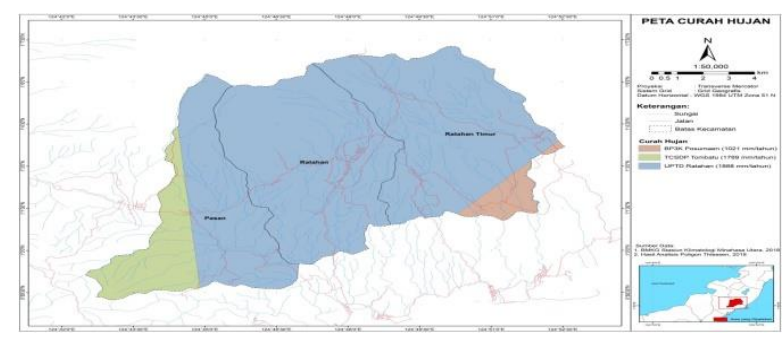

Gambar 3. Peta Curah Hujan di Kecamatan Pasan, Ratahan dan Ratahan Timur

3. Suhu dan Elevasi

Rata-rata suhu udara tahunan di Kabupaten Minahasa Tenggara dari 2014-2017 tertuang pada Tabel 4.

Tabel 4. Rata-Rata Suhu Udara Tahunan di Kabupaten Minahasa Tenggara

\begin{tabular}{cc}
\multicolumn{2}{c}{ Minahasa Tenggara } \\
\hline 2014 & Rata-Rata Suhu udara $\left({ }^{\circ} \mathrm{C}\right)$ \\
2015 & 26,9 \\
2016 & 27,1 \\
2017 & 27,4 \\
27,1 \\
\hline \multicolumn{2}{l}{ Sumber : Minahasa Tenggara dalam Angka Tahun 2015-2018 }
\end{tabular}

Ketinggian wilayah daerah penelitian di Kecamatan Pasan, Ratahan dan Ratahan Timur diatas permukaan laut seperti pada Gambar 4.

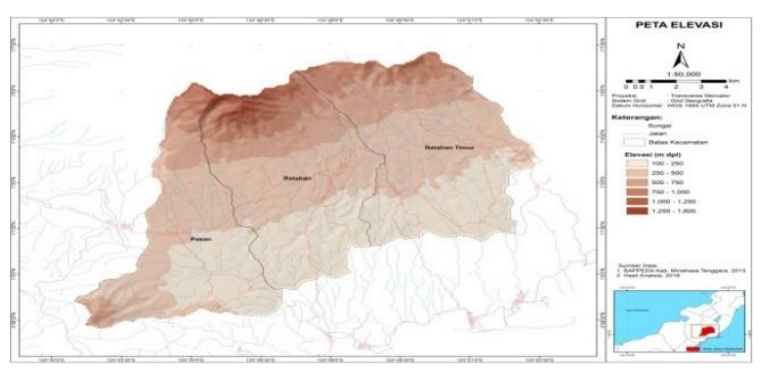

Gambar 4. Peta Elevasi Kecamatan Pasan, Ratahan dan Ratahan Timur
4. Tanah

Sistem klasifikasi tanah, iklim (curah hujan) dan lereng merupakan dasar dalam penentuan zona agroekologi. Tabel 5 memuat hasil analisis jenis tanah menurut kecamatan di daerah penelitian.

Tabel 5. Jenis Tanah di Kecamatan Pasan, Ratahan, dan

\begin{tabular}{ll} 
& Ratahan Timur \\
\hline Kecamatan & Jenis Tanah \\
\hline Ratahan & $\begin{array}{l}\text { Humitropepts, dystrandepts, hydrandepts, eutropepts, } \\
\text { dystropepts, tropohumults, tropudults, troperthents. }\end{array}$ \\
Ratahan & $\begin{array}{l}\text { Dystropepts, humitropepts, tropohumults, eutropepts, } \\
\text { dystrandept. }\end{array}$ \\
Timur & $\begin{array}{l}\text { Humitropepts, dystrandepts, hydrandepts, dystropepts, } \\
\text { tropudalfs, troperthents,eutropepts, euntrandepts, } \\
\text { tropohumults }\end{array}$ \\
& Sumber: Hasil analisis data jenis tanah
\end{tabular}

Penggunaan zonasi agroekologi di daerah penelitian digunakan peta jenis tanah. Gambar 5 merupakan hasil digitasi dan kompilasi data menurut jenis tanah per kecamatan.

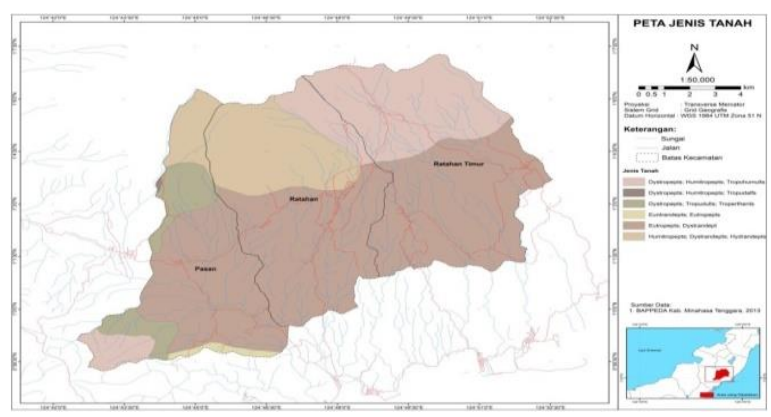

Gambar 5. Peta Tanah Kecamatan Pasan, Ratahan dan Ratahan Timur

\section{Penggunaan Lahan di Kecamatan Ratahan,} Ratahan Timur dan Pasan

Hasil analisis data peta tutupan lahan di Kecamatan Ratahan, Ratahan Timur dan Pasan di peroleh 10 (sepuluh) kelompok tutupan lahan yaitu berupa hutan, hutan sekunder, pemukiman, perkebunan, pertanian campuran, sawah, tanah terbuka, badan air dan alang-alang. Penggunaan lahan yang banyak dijumpai di daerah penelitian berupa perkebunan, pertanian campuran dan sawah serta hutan. Daerah penelitian lebih di dominan yaitu perkebunan seluas $10.144,89$ ha dijumpai pada lahan mulai datar sampai pada agak curam dengan kondisi tanah dystropepts, humitropepts, tropudults, troperthents, eutropepts dystrandept. Perkebunan adalah daerah yang ditumbuhi vegetasi tahunan satu jenis maupun campuran baik dengan pola acak, maupun teratur sebagai batas tegalan. Tutupan lahan yang juga dengan luasan besar dijumpai pada daerah penelitian berupa pertanian campuran diantaranya beberapa tanaman pangan dan hortikultura yang ditanaman pada lahan atau keadaan wilayah berombak sampai dengan agak 
curam dan jenis tanah berupa dystropepts, humitropepts, tropohumults, euntrandepts, eutropepts, dan dystrandept. Tabel 6 memuat hasil analisis penggunaan lahan di 3 Kecamatan yang merupakan lokasi penelitian.

Tabel 6. Penggunaan Lahan di Kecamatan Ratahan, Ratahan Timur dan Pasan

\begin{tabular}{lllll}
\hline \multirow{2}{*}{ Tutupan Lahan } & \multicolumn{3}{c}{ Kecamatan } & \multirow{2}{*}{ Total (Ha) } \\
\cline { 2 - 4 } & Pasan & Ratahan & Ratahan Timur & \\
\hline Alang-Alang & 27,8356 & - & - & 27,8356 \\
Badan Air & 10,5072 & 5,0359 & - & 15,5431 \\
Belukar & - & 368,7324 & - & 368,7324 \\
Hutan & 669,7705 & $1.837,8538$ & $1.136,6067$ & $3.644,23$ \\
Hutan & - & - & 19,4067 & 19,4067 \\
Sekunder & 98,4235 & 131,1625 & 96,7399 & 326,3259 \\
Pemukiman & $3.619,3304$ & $3.108,0739$ & $3.417,4864$ & $10.144,89$ \\
Perkebunan & 506,5752 & 498,1195 & $1.700,6748$ & $2.705,37$ \\
Pertanian & 37,4468 & 210,2152 & 15,0842 & 262,7462 \\
Campuran & 7,1629 & 4,2793 & - & 11,4422 \\
Sawah & $4.977,0521$ & $6.163,4725$ & $6.385,9987$ & $17.526,5233$ \\
Tanah Terbuka & Total & \multicolumn{4}{c}{. } & \\
\hline Sumber: Hasil analisis data peta tutupan lahan Kec. Ratahan, Ratahan Timur \\
\multicolumn{4}{c}{ dan Pasan. }
\end{tabular}

Penggunaan lahan hutan dengan luasan 3.644,23 ha juga dijumpai di 3 Kecamatan dan tepatnya di Kecamatan Ratahan Timur terdapat hutan sekunder seluas 19,4067 ha. Ada juga penggunaan lahan sawah yang tersebar dilokasi penelitian seluas 262,7462 ha yang diusahakan pada kondisi lahan berombak dan berombak berbukit dengan jenis tanah eutropepts (sangat subur) dystrandept, dystropepts; humitropepts; tropohumults. Lahan pertanian yang tidak dimanfaatkan dan dibiarkan di tumbuhi semak/rumput dari hasil kompilasi hanya dijumpai di Kecamatan ratahan seluas 368,7324 ha pada lahan yang bergunung atau lereng dengan kemiringan $>40 \%$. Tutupan lahan tanah terbuka seluas 11,4422 ha, yang merupakan lapangan olah raga atau lahan Galian C yang dijumpai di Kecamatan Pasan dan Ratahan serta alang-alang atau dikenal dengan kusu-kusu tumbuh seluas 27,8356 ha di Kecamatan Pasan pada kemiringan lereng 25-40 \%. Sedangkan luasan pemukiman yang lebih identik dengan kombinasi antara jalan, bangunan, pekarangan dan bangunan itu sendiri yang tersebar di daerah penelitian dengan jumlah total 326,3259 ha.

Hasil analis is penggunaan lahan di Kecamatan Ratahan, Ratahan Timur dan Pasan menggunakan peta skala 1:10.000 (Digitasi Globe Tahun 2017) dihasilkan peta penggunaan lahan di 3 Kecamatan tersebut dapat dilihat pada Gambar 6.

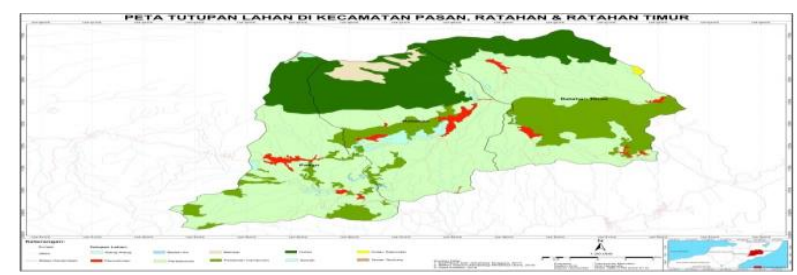

Gambar 6. Peta Tutupan Lahan di Kecamatan Pasan, Ratahan dan Ratahan Timur
6. Rencana Tata Ruang Wilayah Kabupaten Minahasa Tenggara Tahun 2013.

Hasil analisis data peta Pola Ruang Rencana Tata Ruang Wilayah di Kecamatan Pasan, Ratahan dan Ratahan Timur semenjak 2013-2033 dalam pemanfaatan lahan pada kawasan lindung dan kawasan budidaya yang lebih jelasnya dapat dilihat pada Tabel 7.

Tabel 7. Luas Rencana Tata Ruang Wilayah Kecamatan Ratahan, Ratahan Timur dan Pasan

\begin{tabular}{|c|c|c|c|c|}
\hline \multirow[b]{2}{*}{ Tutupan Lahan } & \multicolumn{3}{|c|}{ Kecamatan } & \multirow[b]{2}{*}{ Total (Ha) } \\
\hline & Pasan (Ha) & Ratahan (Ha) & $\begin{array}{c}\text { Ratahan Timur } \\
(\mathrm{Ha})\end{array}$ & \\
\hline $\begin{array}{l}\text { Kawasan Lindung: } \\
\text { Hutan Lindung }\end{array}$ & 691,0765 & $1.650,0198$ & 928,0278 & $3.269,12$ \\
\hline $\begin{array}{l}\text { Kawasan Sekitar Mata } \\
\text { Air }\end{array}$ & - & - & 10,8565 & 10,86 \\
\hline $\begin{array}{l}\text { Lereng diatas } 30 \\
\text { Derajat }\end{array}$ & 193,6384 & - & 28,6400 & 222,28 \\
\hline Resapan Air & 29,5239 & 50,5669 & 193,9865 & 274,08 \\
\hline Sempadan Danau & 85,4258 & 19,8652 & - & 105,29 \\
\hline $\begin{array}{l}\text { Sempadan Sungai } \\
\text { Kawasan Budidaya : }\end{array}$ & 368,1763 & 287,1605 & 481,2201 & $\begin{array}{l}1.136,56 \\
0,00\end{array}$ \\
\hline Pertanian Pangan & & & & \\
\hline $\begin{array}{l}\text { Lahan Kering dan } \\
\text { Perkebunan }\end{array}$ & $3.285,0579$ & $3.783,7408$ & $4.588,2708$ & $11.657,07$ \\
\hline Permukiman & 95,6454 & 130,0168 & 84,0783 & 309,74 \\
\hline $\begin{array}{l}\text { Pertanian Pangan } \\
\text { Lahan Basah }\end{array}$ & 228,5080 & 242,1024 & 70,9186 & 541,53 \\
\hline Total & 4977,0521 & 6.163 .4725 & $6.385,9987$ & 17.526 .5238 \\
\hline
\end{tabular}

Hasil analisis Pola Ruang RTRW Kecamatan Ratahan, Ratahan Timur dan Pasan dari Tabel 7 di peroleh Kawasan Lindung didaerah penelitian berupa hutan lindung gunung soputan dan gunung kawatak, daerah kawasan sekitar mata air, resapan air, daerah aliran sungai dan danau. Sedangkan untuk kawasan budidaya diperuntukkan untuk permukiman, pertanian pangan lahan kering dan perkebunan serta pertanian pangan lahan basah, yang sebarannya dapat dilihat pada Gambar 7.

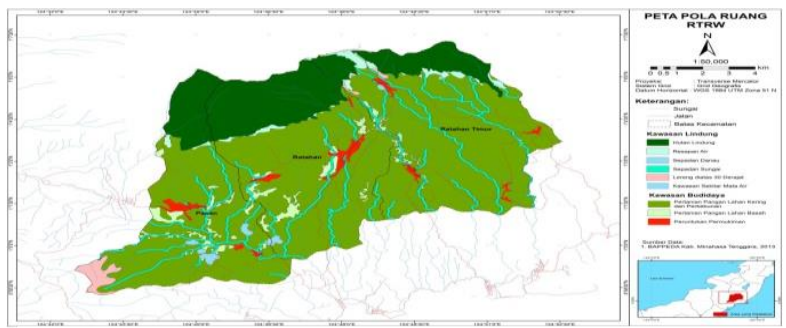

Gambar 7. Peta Pola Ruang RTRW di Kecamatan Pasan, Ratahan dan Ratahan Timur.

7. Zona Agroekologi Kecamatan Pasan, Ratahan dan Ratahan Timur

Konsep pewilayahan pertanian atau pemetaan zona agroekologi (ZAE) adalah penyederhanaan dan pengelompokan agroekologi yang beragam dalam bentuk klasifikasi yang lebih aplikatif yang juga merupakan salah satu metode pengidentifikasian lahan. Berdasarkan hasil overlay peta curah hujan, jenis tanah, dan lereng maka diperoleh 32 (tiga puluh dua) zona agroekologi yang dapat dilihat pada Tabel 8 . 
Tabel 8. Zona Agroekologi di Kecamatan Pasan, Ratahan dan Ratahan Timur

\begin{tabular}{|c|c|c|c|c|c|}
\hline Zona Agroekologi & Kelas Lereng $(\%)$ & Tipe Iklim & Suhu $\left({ }^{\circ} \mathrm{C}\right)$ & Jenis Tanah & Luas (Ha) \\
\hline 1 & $>40$ & B1 & $15-22$ & Dystropepts; Humitropepts; Tropohumults & 1018,38 \\
\hline 2 & $>40$ & $\mathrm{C} 2$ & $>22$ & Dystropepts; Humitropepts; Tropohumults & 175,88 \\
\hline 3 & $15-25$ & B1 & $>22$ & Dystropepts; Humitropepts; Tropohumults & 837,01 \\
\hline 4 & $8-15$ & $\mathrm{C} 2$ & $>22$ & Dystropepts; Humitropepts; Tropohumults & 5,11 \\
\hline 5 & $25-40$ & B1 & $15-22$ & Dystropepts; Humitropepts; Tropohumults & 1360,49 \\
\hline 6 & $25-40$ & $\mathrm{C} 2$ & $>22$ & Dystropepts; Humitropepts; Tropohumults & 232,56 \\
\hline 7 & $8-15$ & $\mathrm{C} 2$ & $>22$ & Dystropepts; Humitropepts; Tropudalfs & 10,55 \\
\hline 8 & $25-40$ & $\mathrm{C} 2$ & $>22$ & Dystropepts; Humitropepts; Tropudalfs & 0,86 \\
\hline 9 & $>40$ & $\mathrm{C} 2$ & $>22$ & Dystropepts; Tropudults; Troperthents & 18,57 \\
\hline 10 & $15-25$ & $\mathrm{C} 2$ & $>22$ & Dystropepts; Tropudults; Troperthents & 110,92 \\
\hline 11 & $15-25$ & B1 & $>22$ & Dystropepts; Tropudults; Troperthents & 338,83 \\
\hline 12 & $8-15$ & $\mathrm{C} 2$ & $>22$ & Dystropepts; Tropudults; Troperthents & 155,10 \\
\hline 13 & $25-40$ & $\mathrm{C} 2$ & $>22$ & Dystropepts; Tropudults; Troperthents & 272,27 \\
\hline 14 & $25-40$ & B1 & $>22$ & Dystropepts; Tropudults; Troperthents & 54,75 \\
\hline 15 & $8-15$ & $\mathrm{C} 2$ & $>22$ & Eutropepts; Dystrandept & 137,35 \\
\hline 16 & $8-15$ & B1 & $>22$ & Eutropepts; Dystrandept & 1155,27 \\
\hline 17 & $25-40$ & B1 & $>22$ & Euntrandepts; Eutropepts & 16,76 \\
\hline 18 & $15-25$ & $\mathrm{C} 2$ & $>22$ & Eutropepts; Dystrandept & 535,19 \\
\hline 19 & $15-25$ & $\mathrm{E}$ & $>22$ & Eutropepts; Dystrandept & 517,90 \\
\hline 20 & $15-25$ & B1 & $>22$ & Eutropepts; Dystrandept & 7275,38 \\
\hline 21 & $25-40$ & $\mathrm{C} 2$ & $>22$ & Eutropepts; Dystrandept & 32,01 \\
\hline 22 & $0-8$ & B1 & $>22$ & Eutropepts; Dystrandept & 14,06 \\
\hline 23 & $>40$ & B1 & $15-22$ & Humitropepts; Dystrandepts; Hydrandepts & 564,70 \\
\hline 24 & $15-25$ & B1 & $>22$ & Humitropepts; Dystrandepts; Hydrandepts & 933,35 \\
\hline 25 & $25-40$ & $\mathrm{C} 2$ & $>22$ & Humitropepts; Dystrandepts; Hydrandepts & 10,52 \\
\hline 26 & $26-40$ & B1 & $15-22$ & Humitropepts; Dystrandepts; Hydrandepts & 1236,71 \\
\hline 27 & $15-25$ & B1 & $>22$ & Dystropepts; Humitropepts; Tropohumults & 0,00 \\
\hline 28 & $16-25$ & B1 & $>22$ & Eutropepts; Dystrandept & 0,00 \\
\hline 29 & $8-15$ & B1 & $>22$ & Euntrandepts; Eutropepts & 97,47 \\
\hline 30 & $9-15$ & $\mathrm{E}$ & $>22$ & Eutropepts; Dystrandept & 36,57 \\
\hline 31 & $25-40$ & B1 & $>22$ & Eutropepts; Dystrandept & 324,61 \\
\hline 32 & $25-40$ & $\mathrm{C} 2$ & $>22$ & Eutropepts; Dystrandept & 62,55 \\
\hline
\end{tabular}

Sumber : Analisis data peta curah hujan, jenis tanah dan kelas lereng.

Tabel 8 menunjukkan bahwa hasil overlay peta curah hujan, kelas lereng dan tipe tanah didapat dari 178 poligon seperti pada lampiran 1 sehingga diperoleh 32 zona agroekologi yang tersebar di daerah penelitian dimana masing-masing zona mempunyai satu jenis tipe tanah, satutipe iklim Oldeman merupakan hasil rata-rata curah hujan di satu stasiun pos hujan, dan satu kemiringan lereng yang bisa tersebar di satu kecamatan atau bahkan disemua kecamatan daerah penelitian, yang penjabarannya dapat dilihat pada Gambar 8.

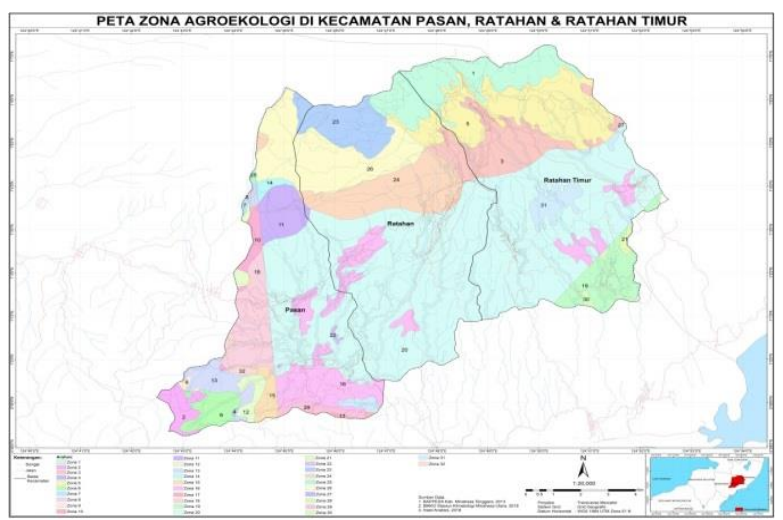

Gambar 8. PetaZAE di Kecamatan Ratahan, Ratahan Timur dan Pasan. 
8. Rekomendasi Pemanfaatan Lahan Berdasarkan Hasil Zona Agroekologi dan RTRW Kabupaten Minahasa Tenggara Tahun 2013

Pemanfaatan lahan berdasarkan zona agroekologi dan pola ruang RTRW Tahun 2013 dari hasil 32 zona dan masing-masing zona memiliki rekomandasi peruntukkannya yang jelasnya pada lampiran. 2. Zona 1 dengan fisiografi daerah bergunung (>40\%), didominan oleh jenis tanah dystropepts, humitropepts dan tropohumults dalam sistem klasifikasi tanah USDA termasuk dalam ordo inceptisol, dengan tipe iklim perudic (B1) pada sebagian besar rezim suhu $15-22^{\circ} \mathrm{C}$ juga ada beberapa poligon yang dikisaran rezim suhu $>22^{\circ} \mathrm{C}$ yang tersebar di Kecamatan Ratahan dan Ratahan Timur dimana tutupan lahan diuntukkan pada belukar, hutan dan perkebunan. Berdasarkan hasil pola ruang RTRW Tahun 2013 dimana sebaran zona 1 berada pada kawasan lindung yang diperuntukkan pada hutan lindung dan didaerah resapan air, yang dimana didaerah penelitian terdapat kawasan hutan lindung gunung soputan dan gunung kawatag, sehingga zona 1 direkomendasikan peruntukkannya pada hutan lindung, resapan air dan agroforestry. Zona agroekologi 2 yang tersebar di Kecamatan Pasan dengan keadaan topografi dan tanah seperti pada zona 1 dengan perataan suhu tahunan sebagian besar $>22^{\circ} \mathrm{C}$, tipe iklim C2 (udic), hasil analisa tutupan lahan diperuntukkan pada perkebunan dan pertanian campuran, dimana pada zona 2 merupakan zona yang berada dikawasan lindung dengan (lereng diatas 30 derajat) maka zona 2 diperuntukkan pada lahan agroforestry atau wanatani.

Sebaran zona 3 di Kecamatan Ratahan dan Ratahan Timur dengan kondisi kemiringan lereng $15-25 \%$ pada tanah yang didominasi seperti zona 1 dan 2, memiliki iklim tipe B1 dengan perataan suhu $>22^{\circ} \mathrm{C}$ dengan hasil analisa tutupan lahan berupa sawah, hutan, pemukiman, hutan sekunder dan perkebunan. Zona 3 yang berada pada kawasan lindung maka dapat direkomendasi penggunaan lahan hutan lindung, kawasan sekitar mata air, sempadan sungai sementara dikawasan budidaya untuk sawah, permukiman, agroforestry, dan juga pemukiman konservasi. Zona 4 yang berada pada kemiringan lereng 8$15 \%$, di kondisi tanah didominan seperti pada zona 1-3, pada iklim C2 dengan rezim suhu isohypertermic $\left(>22^{\circ} \mathrm{C}\right)$ dan diperoleh dari hasil analisa tutupan lahan peruntukkan pada perkebunan sesuai dengan hasil analisa pola ruang maka tetap direkomendasikan untuk perkebunan yang tersebar di Kecamatan Pasan seluas 5.1139 ha di Kecamatan Pasan.

Sebaran zona 5 berada di kawasan lindung dan kawasan budidaya dan untuk dikawasan lindung direkomendasikan untuk hutan lindung dan sempadan sungai dan kawasan sekitar mata air, semantara dikawasan budidaya diarahkan untuk agroforestry, permukiman, perkebunan dan pemukiman konservasi. Sementara untuk hasil pola ruang zona 6 berada pada kawasan lindung atau zona kawasan non budidaya pertanian yang mempunyai karakteristik secara alami tidak layak untuk budidaya pertanian serta kawasan budidaya yang dipeuruntukkan agroforesty dan perkebunan.

Zona 7 dengan kemiringan lereng 8$15 \%$ pada keadaan iklim C2 (udic) didominasi tanah dystropepts, humitropepts dan tropudalfs dengan hasil analisis tutupan lahan untuk perkebunan yang berada pada rezim suhu isohypertermic $\left(>22^{\circ} \mathrm{C}\right)$, dan sesuai hasil analisa pola ruang RTRW Tahun 2013 berada dikawasan lindung (sempadan sungai) dan kawasan budidaya sebarannya di Kecamatan Pasan sehingga dapat direkomendasikan penggunaan lahan berupa perkebunan dan wanatani/agroforestry.

Kecamatan Pasan yang berada disebaran zona 8 dengan luas 0,8550 ha, dengan keadaan lahan dikemiringan lereng 25-40\% dengan tipe tanah, curah hujan, suhu serta hasil analisa tutupan lahan seperti zona 7 dengan hasil pola ruang RTRW Tahun 2013 direkomendasikan penggunaan lahan untuk perkebunan. Zona 9 dengan kemiringan lereng $>40 \%$, pada iklim $\mathrm{C} 2$ dengan rezim suhu isohypertermic $\left(>22^{\circ} \mathrm{C}\right)$ dimana hasil tutupan lahan menunjukkan penggunaan lahan perkebunan dan pertanian campuran sehingga berdasarkan analisis pola ruang RTRW Tahun 2013 berada dikawasan lindung maka direkomendasikan untuk agroforesty pada Kecamatan Pasan. Zona 10 dan 11 yang 
memiliki kelerengan, jenis tanah, Iklim C2 dan B1 serta rezim suhu yang sama pada dikawasan lindung maupun kawasan budidaya maka dapat diarahkan pada pemanfaatan lahan berupa hutan lindung, sempadan sungai dan resapan air serta perkebunan, agroforesty, dan hutan produksi yang penyebarannya sebagian besar di Kecamatan Pasan juga di Ratahan.

Sebaran zona 12, 13 dan 14 dikemiringan lahan $8-15 \%$ dan $25-40 \%$ didominasi pada tanah dan iklim dan resim suhu yang seperti pada zona sebelumnya (10 dan 11) berdasarkan pola ruang didaerah kawasan lindung dan kawasan budidaya maka peruntukkannya direkomendasikan untuk hutan lindung, sempadan sungai dan resapan air serta agroforesty, perkebunan, pertanian campuran, dan hutan produksi yang tersebar di Kecamatan Pasan dan Ratahan. Pada Kecamatan Pasan juga hampir sama terdapat sebaran zona 15 dengan kemiringan lereng 8-15, iklim tipe $\mathrm{C} 2$, dengan tipe tanah yang didominan berupa tanah eutropepts dan dystrandept (subur yang bertekstur lempung hingga berpasir), dalam rezim suhu isohypertermic $\left(>22^{\circ} \mathrm{C}\right)$ dikawasan lindung karena berada pada daerah aliran sungai maka di rekomendasi untuk sepdan sungai sementara pada kawasan budidaya direkomendasikan untuk tanaman perkebunan dan agroforesty. Zona 16 yang merupakan salah satu zona yang luasannya paling besar dijumpai pada banyaknya jumlah nomor poligon seperti pada lampiran. 2 direkomendasikan untuk perkebunan, permukiman, agroforesty, pemukiman konservasi, sawah, dan pertanian campuran.

Sebaran zona 17 di Kecamatan Pasan dengan keadaan wilayah agak curam/curam (25-40\%), didominasi oleh jenis tanah eutrandepts dan eutropepts dengan iklim tipe B1 pada perataan suhu $>22^{\circ} \mathrm{C}$ berdasarkan hasil analisis pola ruang berada dikawasan budidaya maka dapat diarahkan penggunaan lahan untuk pertanian campuran dan perkebunan. Begitu halnya seperti zona 18 dan zona 19 yang sebarannya hanya di Kecamatan Pasan serta Ratahan Timur berdasarkan parameter fisik, dan hasil tutupan lahan serta pola ruang direkomendasikan penggunaan lahan untuk sempadan sungai, permukiman, perkebunan, pemukiman konservasi, dan pertanian campuran. Berdasarkan kondisi iklim E dimana zona 19 berada di daerah kering karena memiliki curah hujan dengan jumlah bulan kering yang lebih dari bulan lembab karena dizona ini berada dekat dengan daerah pantai. Zona 20 yang merupakan salah satu zona paling yang luasnya cukup besar dan tersebar disemua daerah penelitian berdasarkan hasil analisis parameter fisik, dan suhu $>22^{\circ} \mathrm{C}$ dengan kondisi tutupan lahan serta pola ruang RTRW tahun 2013 diperoleh arahan penggunaan lahan seperti halnya zona 19. Rekomendasi yang diperoleh dari analisis sebaran zona 21 seperti yang tercamtum dalam lampiran. 2 maka diarahkan untuk penggunaan lahan pertanian campuran yang didaerah Kecamatan Ratahan Timur.

Kecamatan Pasan yang terdapat sebaran zona 22 dengan keadaan lahan yang datar dimana kemiringan lereng dikisaran 0-8\%, pada iklim B1 dengan rezim suhu isohypertermic didominan oleh tanah seperti pada zona 21 dimana penggunaan lahan sekarang diperuntukkan pada badan air dan perkebunan serta berada dikawasan lindung yang karena didaerah sempadan danau, daerah penelitian dialiri danau mongkaw ok dan lahendong, sementara untuk kawasan budidaya diarahkan penggunaan lahan perkebunan. Lahan dengan kondisi relatif datar lebih diarahkan bagi pertanian tanaman palawija, hortikultura serta buah-buahan ataupun tanaman tahunan berupa tanaman perkebunan lainnya serta untuk keberlanjutan swasembada pangan dalam pengembangan tanaman perkebunan sebaiknya diarahkan pada lahan-lahan dengan kemiringan > $8 \%$ sedangkan lahan dengan kemiringan $<8 \%$ untuk pengembangan tanaman pangan (Napisah dan Noor, 2016).

Zona 23-27 yang penyebarannya di kecamatan Ratahan dan Pasan, berdasarkan hasil analisis seperti pada lampiran.2 diperuntukkan pada hutan lindung, pemukiman konservasi, pertanian campuran, permukiman, agroforesty, sawah, perkebunan dan hutan produksi. Sebaran sebaran zona 28-30 yang berada dikawasan budidaya berdasarkan hsil analisis maka diperuntukkan pada perkebunan dan pertanian campuran. Berdasarkan hasil analisis pada zona 31 dan 32 berada dikawasan lindung dan budidaya yang peruntukkan untuk agroforesty, perkebunan dan pertanian campuran dimana yang perolehannya secara lebih terperinci hasilnya seperti pada Gambar 9. 


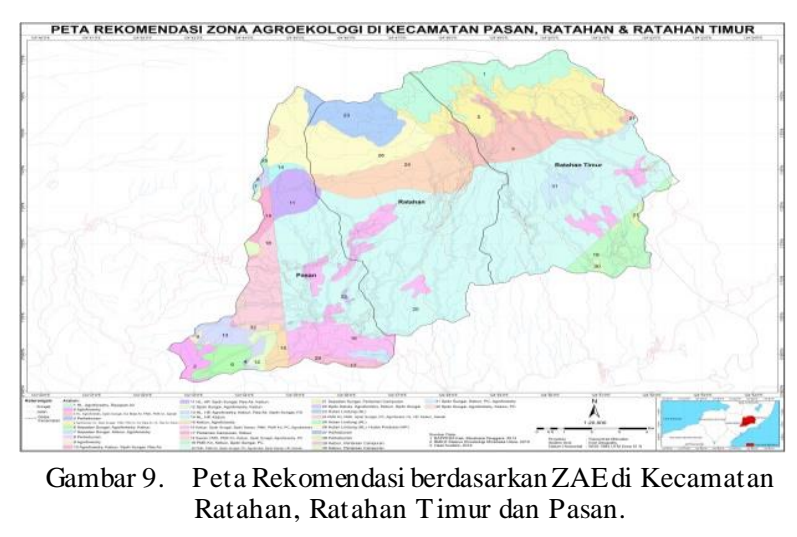

KESIMPULAN DAN SARAN

Kesimpulan

Konsep pemanfaatan lahan diKecamatan Ratahan, Ratahan Timur dan Pasan hasil peta zona agroekologi dengan menggunakan SIG diperoleh 32 zona dari hasil analisis data jenis tanah dan kemiringan lereng serta tipe iklim. Hasil analisis peruntukannya yang sesuai dengan kondisi penggunaan lahan (tutupan lahan) serta keluaran peta pola ruang RTRW Kabupaten Minahasa Tenggara tahun 2013 berdasarkan zona agroekologi maka disetiap zona sesuai untuk penggunaan lahan di kawasan lindung direkomendasikan pada hutan lindung, daerah resapan air, sempadan sungai dan sempadan danau kawasan sekitar mata air. Sementara dikawasan budidaya direkomendasikan penggunaan lahan untuk agroforesty, sawah, permukiman, pertanian campuran, pemukiman konservasi, perkebunan serta hutan produksi.

\section{Saran}

Guna menghadapi tuntutan pembangunan daerah khususnya di Kecamatan Pasan, Ratahan dan Ratahan Timur Kabupaten Minahasa yang akan berdampak pada konversi lahan maka dalam perencanaan tata guna lahan untuk rancangan pengembangan serta pengelolaan lahan dapat mengacu pada arahan pemanfaatan lahan berdasarkan zona agroekologi.

Guna menghadapi tuntutan pembangunan daerah khususnya di Kecamatan Pasan, Ratahan dan Ratahan Timur Kabupaten Minahasa yang akan berdampak pada konversi lahan maka dalam perencanaan tata guna lahan untuk rancangan pengembangan serta pengelolaan lahan dapat mengacu pada arahan pemanfaatan lahan berdasarkan zona agroekologi.
Kurangnya titik pos hujan dan belum optimalnya hasil pengamatan pada pos hujan sehingga adanya kerenggangan data, dengan tidak adanya alat ukur suhu, kelembaban bahkan belum tersedianya peta iklim khususnya di Kabupaten Minahasa Tenggara maka perlu dilakukannya penelitian lanjut guna menghasilkan peta agroklimat klasifikasi iklim di Kabupaten Minahasa Tenggara yang dapat dijadikan referensi dalam penentuan kebijakan Pemerintah Kabupaten Minahasa Tenggara yang tidak hanya di Kecamatan Ratahan, Kecamatan Ratahan Timur dan Kecamatan Pasan dalam perencanaan tata guna lahan untuk rancangan pengembangan serta pengelolaan lahan usaha pertanian.

\section{DAFTAR PUSTAKA}

Badan Pusat Statistik. Kabupaten Minahasa Tenggara Dalam Angka 2018.

FAO. 1976 A Framework For Land Evaluation pada situs : https://www.mpl.ird.fr> pdf docs> framele.

Napisah K dan A Noor. 2016. Karakteristik Lahan dan Arahan Komoditas Berdasarkan Agroekologi Zone untuk Pengembangan Pertanian di Kabupaten Tanah Laut Kalimantan Selatan. Prosiding Seminar Nasional Inovasi Teknologi Pertanian Banjarbaru, 20 Juli 2016.

Oldeman L.R dan Darmayanti. 1977. An Agroclimat Map Sulawesi. Contr. Centr. Rest.Inst.Afric. Bogor.

Peraturan Daerah Kabupaten Minahasa Tenggara Nomor 3 Tahun 2013 Tentang Rencana Tata Ruang Wilayah Kabupaten Minahasa Tenggara Tahun 2013- 2033. 